fingers at one metre, one counted M.B.E. at 1.5 metres, and five were not improved by the operation, the failure being due to iritis in one case and to secondary changes in the coats of the eye in four cases.

I have refrained from commenting on this series as far as possible, leaving the facts to speak for themselves, and delaying remarks till after the publication of 300 more cases. It would, however, be an act of discourtesy to Professor McKeown of Belfast if I omitted to acknowledge the debt I owe him for allowing me to witness his method of using the irrigating apparatus which bears his name and which has since given me the best results I have yet had in cataract extraction. The irrigator has reduced the vitreous losses of this series to 2 per cent. ; by emptying the capsule and chamber of débris it has minimised the need for subsequent capsulotomy and has enabled me to dispense with the introduction of instruments into the eye after the escape of the nucleus; it has been of great value in clearing the chamber of blood, \&c., and so facilitating the subsequent steps of the operation in a class of cases which otherwise are liable to prove hazardous ; by gently and evenly replacing the iris (even when impacted in the edges of the section) it has been most valuable, and it has expedited recovery inasmuch as it left behind so little cortex to be absorbed. Finally, it has enabled me to operate fearlessly on a large number of very immature cataracts which, before using it, I could not have ventured to interfere with. Against these marked advantages I know of no disadvantage which it possesses

Madras.

\section{TAPE-WORMS AS A POSSIBLE CAUSE OF DIABETES.}

BY JOSEPH EDWARD JUDSON, M.R.C.S. ENG., L.R.C.P. LOND.,

HOUSE SURGEON, DISTRICT INFIRMARY, ASHTON-UNDER-IYNE.

THE two cases which I now describe, in which tape-worms were found to be associated with glycosuria, have led me to suppose the possibility of the existence of a direct connexion between the worms and the disease in question.

CASE 1.-A man, aged 50 years, came to me on March 28th, 1901, at the Manchester Workhouse, Crumpsall, complaining of passing tape-worms, segments of which he had found for some weeks previously. He complained of nothing else except that he was losing flesh. On examination the lungs were found to be the seat of early phthisis and the liver to be enlarged. The specific gravity of the urine was 1035 and its reaction was acid; there were a trace of albumin and a large quantity of sugar. The man passed on an average 80 ounces of urine per diem and each day it contained a large quantity of sugar which was detected by Fehling's test and by the fermentation test. The patient was treated in the usual way with filix mas for the tape-worms, segments of which were evacuated, but the head of the worm could not be found. I put him on a diabetic diet and gave him pancreatic extract. He gained flesh and the sugar passed per diem became less in quantity but it was never altogether absent. In June and September he again passed segments of a tænia solium and on each occasion he was treated with filix mas but the head of the worm was never discovered on either occasion. On Oct. 7th he died and at the necropsy the liver was found to be considerably enlarged with a tendency to cirrhosis. The pancreas was apparently normal but was not examined histologically and the lungs were the seat of tuberculosis.

CASE 2.-A man, aged 40 years, was aclmitted into the District Infirmary, Ashton-under-Lyne, on Oct. 8th, 1902, with gangrene of the big toe. His previous health had been very good but according to his own statement he had been troubled during the last three years with tape-worms. 'The specific gravity of the urine was 1035 and its reaction was neutral ; there was no trace of albumin but a large quantity of sugar. The man passed on an average 90 ounces of urine per diem and had a slightly increased thirst. It was decided not to amputate the leg, so on the 17 th the patient returned to his home.

The theory which occurred to me was that the head of the tape-worm might very possibly get into the pancreatic duct and become well fixed to the wall by means of its hooklets and through the inflammatory change which it would produce cause an occlusion of that duct. ${ }^{-}$. We know that extirpation of the pancreas brings on glycosuria in animals owing to the absence of the internal secretion the presence of which is necessary in order that the normal assimilative processes can take place with the glycogen. If the duct be occluded, no doubt the glano will in time atrophy and so. become useless. This would then exhibit the same condition as if it had been extirpated. I am well aware that it may be considered rash to advance such a theory on so little evidence, but $I$ can quite see the possibility of the symptoms of diabetes, which in the two cases above were only discovered on examining the urine, being overlooked unless such an examination had been made; and $I$ take it that not many practitioners who are treating cases of tape-worms would examine the urine of those patients for sugar.without some subjective indications for so doing.

Ashton-under-Lyne.

\section{CASE OF A LARGE DERMOID CYST COMPLICATING LABOUR.}

\section{BY BRYCE J. MACAULAY, L.R.C.P., L.R.C.S. EDIN.,} L.F.P. \& S. GLASG.,

LATE CLINICAL ASSISTANT, HOSPITAL FOR CONSUMPTION, BROMPTON.

I RECORD the following case as being very uncommon and of unusual interest, more especially from the fact that the patient enjoyed "splendid health" all through the pregnancy and that the presence of the cyst was quite unsuspected and in the absence of symptoms was, $I_{4}$ venture to. think, absolutely undiagnosable. As regards previous history the patient commenced to menstruate at the age'of about 15 years and was always "quite regular." One miscarriage occurred about three months after marriage. Coitus was always attended with pain.

I was summoned to attend a primipara, aged 27 years, on the evening of Sept. 21st, 1902. who was said to have been in labour since the morning. 'The pains were not strong, the os was dilating slowly, and the bead could be felt presenting apparently in the left occipito-anterior position. As the pains continued feeble and the os was dilating: very slowly I left. The pains gradually passed off and the patient slept through the night. On my visit next morning about midday ( $I$ had not again been summoned) I was informed that the labour pains had again started about 11 A.M. On examination per vaginam I found very little difference in the size of the os. She was visited at intervals of a few bours during the 22nd and although by the evening of that day the os was fully dilated and the pains were very severe no progress seemed to be made by the head. After consultation with Mr. J. Butler it was decided to adnivister chloroform and to deliver with forceps (the membranes had been ruptured previously). The forceps was introduced comfortably and with no difficulty and traction was made in the direction of the axis of the brim, but it was noticed that notwithstanding the traction the head did not budge in the slightest. On releasing the traction momentarily, without any warning there appeared extruded from the vulva a cyst rather larger than the foetal head and attached by a loner pedicle. The question now arose, What was this? was it a cystocele? A catheter was passed and the urine was drawn off but the swelling did not diminish and a pedicle could be felt attached. Was it a degeneration of the amnion? for it was dotted about with hard masses somewhat resembling yellow elastic tissue. As there were prolapse of the funis and some hæmorrhage the question of placenta prævia was even entertained but the insertion of the cord could not be felt and the tumour was too cystic. After consultation it was decided to remove the forceps and to puncture the cyst. This was done and a thick, green, pultaceous material was extruded. An incision was now made and a large quantity of matted hair was removed. The empty cyst with its long pedicle was brought down and retained outside the vulva by means of a ligature. The forceps was again introduced and the child was easily delivered (dead) with the placenta which followed a few minutes later. As the pulse was at this time 120 the patjent was kept under observation for two hours and $\frac{1}{10}$ th of a grain of ergotinin was given hypodermically before our departure. The removal of the cyst was now the question.

Dr. Robert Boxall, assistant obstetric physician to the 